\title{
DIREITOS E GARANTIAS FUNDAMENTAIS: DIREITO DE SAÚDE
}

\author{
Fernando da Silva Luque ${ }^{1}$
}

\section{RESUMO}

O presente artigo científico expõe sobre direitos e garantias fundamentais à saúde, descrevendo à distribuição de medicamentos, observados os institutos da reserva do possível e o princípio do mínimo existencial, dos primórdios normativos pátrios à Magna Carta. Expõese, em seguida, sobre a eficácia dos direitos sociais, a responsabilidade entre Estado, Município e a União no custeio dos remédios face à vulnerabilidade e urgência do cidadão, o atendimento digno e respeitoso, e o mínimo existencial. A pesquisa adota análise teórica, estabelecendo uma organização coerente de ideias a partir dos mais consagrados autores que discorreram sobre o tema.

Palavras-chave: Direitos Fundamentais; Garantias; Direito de Saúde; Mínimo Existencial e Reserva do Possível; Políticas Públicas.

\section{FUNDAMENTAL RIGHTS AND GUARANTEES: HEALTH LAW}

\begin{abstract}
This scientific article discusses fundamental rights and guarantees to health, describing the distribution of medicines, observing the institutes of the reserve of the possible and the principle of minimum existential, from the normative beginnings of the country until the Constitution. It then discusses the effectiveness of social rights, the responsibility between the State, the Municipality and the Union to fund medicines in the face of vulnerability and urgency of the citizen, dignified and respectful care, and the existential minimum. The research adopts theoretical analysis, establishing a coherent organization of ideas from the most well-known authors who discussed the topic.
\end{abstract}

Keywords: Fundamental Rights; Guarantees; Health Law; Existential Minimum and Reserve of the Possible; Public policy.

\section{INTRODUÇÃO}

\footnotetext{
${ }^{1}$ Fernando da Silva Luque é advogado, mestrando em Direito Processual Civil pela UNINOVE, pós graduado em Direito Processual Civil pela FAVENI, pós graduando em Direto Digital, Direito de Família e Sucessões e Direito Contratual pela Escola Superior de Advocacia - ESA e graduado em Administração Pública pela UNISUL e Direito pelo UNIFIEO.
} 
Esta pesquisa tem como objetivo geral abordar o tema "Direitos Garantias Fundamentais de Saúde", apresentando à saúde como um dos direitos sociais classificados no caput do artigo $6^{\circ}$ da Constituição Federal de 1998, sendo assim, um dever do Estado e um Direito Constitucional de todos. Seu cumprimento tem vigência direta e imediata, recusando a “interpositio legislatoris”, visto que na prática, o que está em questão é o direto à sobrevivência do ser e à vida.

No corpo social brasileiro, tendo em vista que considerável parte da população não tem condições de arcar com os custos implicados com a compra de remédios, ainda mais aqueles cuja ministração é necessária à sua sobrevivência. A esses cidadãos resta, então, socorrer-se do Poder Público para o guarnecimento de medicamentos, a título gracioso, mas na maioria das vezes, não obtêm sucesso, especialmente quanto aos remédios mais custosos, fato que os obriga a recorrerem à via jurídica, para o asseguramento ao seu direito, com base na garantia constitucional de acesso à Justiça, onde ingressarão por meio das tutelas de urgência, para alcançarem seus objetivos. $\mathrm{O}$ assunto submerge em desgastantes contendas jurídicas, principalmente quando diversas liminares com pedidos de fornecimento de tratamento médicos e medicamentos são interpostas em face do Município, Estado e União e os referidos entes públicos tentam evadir-se de seus encargos, relegando uns aos outros o dever que lhes é comum e, por vezes, por questões de cunho basicamente partidário-eleitoral.

A escolha deste tema terá a sua justificativa por conhecer as políticas de saúde aplicadas no Brasil, enfatizando o direito como fundamental, abordando a questão da competência dos entes federativos em matéria de saúde, salientando que a Constituição Federal não isentou qualquer ente federativo da incumbência de proteger, defender e cuidar da saúde,

A problemática que aqui se destaca é pelo fato de apesar de ser garantida constitucionalmente, a saúde enfrenta um grave obstáculo que se refere à efetividade das prestações positivas pelo Estado, razão pela qual hoje se tem inúmeras ações judiciais pleiteando tal direito.

Para o desenvolvimento da pesquisa, o método a ser utilizado será inicialmente o lógico-dedutivo, onde se traça, inicialmente, o sistema de referência bibliográfico adotado e delimita-se o objeto da pesquisa, desenvolvendo-se, assim, as premissas fundamentais, notadamente, as relativas ao direito de saúde como direito constitucional fundamental. 


\section{A SAÚDE COMO DIREITO CONSTITUCIONAL FUNDAMENTAL}

Cumpre salientar a definição do que seja "direito”, termo cuja simples análise semântica revela sua complexidade. De fato, a palavra direito refere-se a um ramo do conhecimento humano, a ciência do direito, ao mesmo tempo em que esclarece seu objeto de estudo: o direito, um sistema de normas que regula o comportamento dos homens em sociedade. Muitas vezes emprega-se a palavra direito em sentido axiológico como sinônimo de justiça e muitas outras em sentido subjetivo, é o meu direito; trata-se, como ensina Reale (1976) da "regra de direito vista por dentro, como ação regulada”. Kelsen (1985), filósofo do direito alemão, partindo da análise linguística chegou à conclusão de que o significado da palavra Recht (direito, em alemão) e de suas equivalentes em outros idiomas (Law, Droit e Diritto para o inglês, francês e italiano, respectivamente) é o mesmo: "ordens de conduta humana”. (DALLARI, 1988).

A segurança de oferta de cuidados de saúde de mesmo plano a todos que deles carecem, também contrapõe à reinvindicação da igualdade. Enquanto direito coletivo à saúde, pendente novamente da prática de desenvolvimento do Estado. Somente o Estado que contiver o seu direito ao desenvolvimento célebre poderá avalizar as mesmas medidas de proteção e iguais cogitados para a recuperação da saúde para toda a sociedade.

O direito à saúde, de forma irrestrita, nasce considerado como direito fundamental social no artigo 6, “caput” e no artigo 196 da Constituição Federal, devendo o Estado prover as condições indispensáveis ao seu pleno exercício.

Leciona Gouvêa (apud SLAIBI, 2019) em seu brilhante artigo sobre o tema, que os direitos fundamentais têm ressurgido, em vários países e contextos discursivos, com diferentes nomenclaturas. Comenta que a doutrina francesa mais preocupada em enaltecerlhes o caráter limitador da potestas estatal, prefere chamá-los de liberdades públicas; ao passo que os estudiosos ligados à tradição anglo-saxônica preferem a expressão: direitos civis, "civil rights", reforçando assim sua vinculação com a temática da cidadania e de seus reconhecimentos no âmbito da esfera pública (civitas); os alemães já se preocupam mais em traçar-lhes uma fundamentação transcendente, frisando a essencialidade desses direitos através do uso da expressão: direitos fundamentais. 
No âmbito das ciências sociológicas e do direito internacional, esclarece Gouveia, tornou-se vulgar a designação de direitos humanos, a qual ressalta sua pertinência ao homem independentemente de qualquer outra circunstância. A doutrina constitucionalista sobre esses direitos, baseada, sobretudo na experiência da Carta de Bonn, incorporou a terminologia alemã. (GOUVÊA apud SLAIBI, 2019).

Como é sabido, o direito à vida ocupa o topo das considerações humanitárias. Os próprios juristas, que observam com receio a afirmação de tábuas de valores e o significado de litígios jurídicos a partir de conceitos puramente axiológicos, aderem com a preferência da vida sobre as demais propriedades jurídicas.

É oportuno o comentário de Silva (2006) sobre a inserção do direito à saúde na Constituição Federal:

\footnotetext{
É espantoso como um bem extraordinariamente relevante à vida humana só na Constituição de 1988 tenha sido elevado à condição de direito fundamental do homem. E há de informar-se pelo princípio de que o direito igual à vida de todos os seres humanos significa também que, nos casos de doença, cada um tem direito a tratamento condigno de acordo com o estado atual da Ciência Médica, independentemente de sua situação econômica, sob pena de não ter muito valor sua consignação em normas constitucionais.
}

Segundo Ingo Sarlet (1998), o artigo 196 é um daqueles dispositivos da Constituição que, tradicionalmente, seriam considerados meramente programáticos, a despeito de qualificar a saúde como "direito de todos e dever do Estado". Isto porque o termo saúde, à vista de seu caráter genérico, dificulta a definição de um campo preciso de investigação. Em tese, seria possível aventar uma infinidade de medidas que contribuiriam para a melhoria das condições de saúde da população, decorrendo daí a necessidade de precisar-se que meios de valorização da saúde poderiam ser postulados judicialmente.

O novo conceito de saúde transcrito pelo Texto Maior de 1988 alega as suas peremptórias e condicionantes (alimentação, moradia, saneamento, renda, meio ambiente, trabalho, transporte, educação etc.), e impõe aos órgãos que constituem o Sistema Único de Saúde o dever de adaptar-se a esses fatos sociais e ambientais e ao Governo o de determinar políticas públicas combinadas com a ascensão do costume de vida da população.

\section{A EFICÁCIA DOS DIREITOS SOCIAIS}


Os direitos fundamentais podem ser definidos como um conjunto de normas, princípios, prerrogativas, deveres e institutos inerentes à soberania popular, que garantem a convivência pacifica, digna livre e igualitária, independentemente de credo, raça, origem, cor condição econômica ou status social, tudo isso baseado no principio da dignidade da pessoa humana. (CARLOS NETO; DENDASCK; OLIVEIRA, 2016)

No entanto, para José Afonso da Silva, se conceituar os direitos fundamentais tornase uma difícil tarefa diante das diversas transformações no passar do tempo, veja-se:

\begin{abstract}
A ampliação e transformação dos direitos fundamentais do homem no envolver histórico dificulta definir-lhes um conceito sintético e preciso.

Aumenta essa dificuldade a circunstancia de se empregarem varias expressões para designá-los, tais como: direitos naturais, direitos humanos, direitos do homem, direitos individuais, direitos públicos subjetivos, liberdades fundamentais, liberdades públicas e direitos fundamentais e direitos fundamentais do homem. (SILVA apud CARLOS NETO; DENDASCK; OLIVEIRA, 2016)
\end{abstract}

Acontece que a maior dificuldade a ser enfrentada neste tópico se refere à aplicabilidade e êxito desses direitos, pois como se sabe, a saúde está positivada no rol dos direitos sociais.

Em relação à eficácia dos direitos sociais é necessário o entendimento não só da norma jurídica em sentido amplo, mas a abordagem da mesma com outros sistemas, tais como: político, econômico, social e histórico.

Faz-se necessário também a diferenciação de vigência e eficácia da norma, conforme abaixo:

O normativismo distingue, com precisão, a vigência da eficácia. A lição de Kelsen é bastante clara a esse respeito. A vigência da norma, para ele, pertence à ordem do dever-ser, e não à ordem do ser. Vigência significa a existência especifica da norma; eficácia é o fato de que a norma é efetivamente aplicada e seguida; a circunstancia de que uma conduta humana conforme a norma se verifica na ordem dos fatos. (SILVA, 2006, p. 64)

Ainda que haja essa confusão, para Ana Paula de Barcellos, a eficácia jurídica da norma está ligada de modo direto com a fundamentalidade social, conforme afirma abaixo:

O primeiro critério que orienta a identificação das modalidades de eficácia jurídica aos enunciados normativos diz respeito ao que se pode denominar de fundamentalidade social da circunstância por ele regulada, que nada mais é que seu grau de importância ou relevância social. Esse é o parâmetro logico que orienta a 
política legislativa de modo geral. Quanto mais fundamental para a sociedade for à matéria disciplinada pelo dispositivo e, consequentemente, os efeitos que ele pretende sejam produzidos, mais consistente deverá ser a modalidade de eficácia jurídica associada (...). (BARCELLOS apud CARLOS NETO; DENDASCK; OLIVEIRA, 2016)

Para produzir os efeitos jurídicos almejados, a eficácia jurídica dos direitos sociais são divididas em normas de eficácia limitada, eficácia plena e eficácia contida, conforme explicado abaixo.

As normas de eficácia plena possuem aplicação imediata e, sendo assim, independem de legislação consecutiva para sua plena execução. Afirma-se ainda que:

São aquelas que, desde a entrada em vigor da Constituição, produzem, ou tem possibilidade de produzir, todos os efeitos essenciais, relativamente aos interesses, comportamentos e situações, que o legislador constituinte, direta e normativamente, quis regular. (SILVA apud CARLOS NETO; DENDASCK; OLIVEIRA, 2016)

As normas constitucionais de eficácia contida são que retêm caráter imperativo, mas também são limitadoras do poder público, conforme se constata:

As normas de eficácia contida são aquelas que o legislador constituinte regulou suficientemente os interesses relativos à determinada matéria, mas deixou margem a atuação da restritiva por parte da competência discricionária do Poder Público, nos termos que a lei estabelecer ou nos termos de conceitos gerais nela enunciados. (SILVA apud CARLOS NETO; DENDASCK; OLIVEIRA, 2016)

Sendo assim, vê-se que o regimento de aplicabilidade dos direitos sociais é exatamente igual ao dos direitos e garantias fundamentais. Ou seja, possuem aplicabilidade imediata conforme dispõe o $\S^{\circ}$ do artigo $5^{\circ}$ da Constituição Federal/1988.

$\mathrm{Na}$ investida de dar uma breve noção, seguem a seguir algumas discussões da

\section{eficácia dos direitos sociais na Constituição.}

Muito se discute na doutrina sobre a eficácia e sobre a aplicabilidade dos direitos constitucionais. Porém, independente da forma de positivação, as normas de direitos fundamentais devem gerar um mínimo de efeitos jurídicos, pois como visto toda norma possui eficácia e aplicabilidade. No entanto, é o grau de eficácia dos direitos fundamentais sociais que será determinado pela forma de positivação na constituição e das peculiaridades do seu objeto. (SARLET apud CARLOS NETO; DENDASCK; OLIVEIRA, 2016). 
Atualmente, o maior problema não se refere à garantia dos direitos, mas quanto à ausência de eficiência das normas constitucionais, veja-se:

\begin{abstract}
O problema fundamental em relação aos direitos do homem, hoje, não é tanto o de justifica-los, mas o de protegê-los (...). Não se tratam de saber quais e quantos são esses direitos, qual a sua natureza e seu fundamento, se são direitos naturais ou históricos, absolutos ou relativos, mas sim qual é o modo mais seguro de garanti-los, para impedir que, apesar das solenes declarações eles sejam continuamente violados. (BOBBIO, 1992, p. 24-25)
\end{abstract}

Sendo assim, a eficácia limitada dos direitos fundamentais sociais não se deve apenas a falta de leis ordinárias.

O problema maior é a não prestação real dos serviços sociais básicos pelo poder público, já que a grande maioria das normas para o exercício dos direitos sociais já existe. Vêse que o problema certamente está na "formulação, implementação e manutenção das respectivas políticas publicas e na composição dos gastos nos orçamentos da União, dos Estados e dos Municípios". (CARLOS NETO; DENDASCK; OLIVEIRA, 2016).

Outro problema que se discute bastante na doutrina é sobre a determinação dos elementos constitutivos dos direitos fundamentais sociais que se liga ao fato de esses direitos apenas existirem "quando as leis e as políticas sociais o garantirem. Por outras palavras: é o legislador ordinário que cria e determina o conteúdo de um direito social" (CARLOS NETO; DENDASCK; OLIVEIRA, 2016).

Ao enfrentar a problemática da eficácia dos direitos fundamentais sociais, não há como desconsiderar sua função precípua de direitos a uma prestação, assim como a sua forma de positivação no texto constitucional, já que ambos os aspectos, a toda evidencia, constituem fatores intimamente vinculados ao grau de eficácia e aplicabilidade dos direitos fundamentais, como já mencionado. (CARLOS NETO; DENDASCK; OLIVEIRA, 2016).

Outra questão que prejudica a eficácia dos direitos fundamentais é a chamada 'reserva do possível', que vem sendo utilizada para indicar a limitação dos recursos perante a necessidade de aplicação para a garantia dos direitos fundamentais e sociais. Conforme demonstra Barcellos (apud CARLOS NETO; DENDASCK; OLIVEIRA, 2016):

O debate em torno dessa questão tem sido identificado no Brasil por meio da expressão reserva do possível e popularizado, em boa parte, pelo empenho da Administração Pública em divulga-lo e argui-lo nas mais diversas demandas, a pretexto do sempre iminente apocalipse econômico. 
Acontece que a ausência de recursos orçamentários não podem ser empecilhos para a garantia dos direitos sociais, que são os requisitos essenciais da vida humana, pois assim, acaba por infringir o preceito básico e fundamental da Constituição Federal: o princípio da dignidade humana.

Sendo assim, a garantia a um mínimo existencial é condição necessária para a sobrevivência de um individuo, pois se não possui os requisitos necessários para uma vida digna, os direitos sociais prestacionais não estão sendo eficientes. E no que tange ao mínimo existencial destinado à saúde, infringe-se também o direito à vida, pois sem saúde não se vive.

Executadas estas considerações, para não romper a metodologia do discurso, conduzindo o pensar para ponto distante do núcleo do artigo, será examinado o princípio da reserva do possível, conforme será demonstrado a seguir.

Para discorrer sobre o assunto, é necessário primeiro se conceituar o princípio da reserva do possível, anote-se:

\begin{abstract}
A expressão reserva do possível procura identificar o fenômeno econômico da limitação dos recursos disponíveis diante da necessidade quase sempre infinitas a serem por elas supridas. No que importa ao estudo aqui empreendido, a reserva do possível significa que, para além das discussões jurídicas sobre o que se pode exigir judicialmente do Estado - e em ultima analise da sociedade, já que é esta que o sustenta - é importante lembrar que há um limite de possibilidades materiais para esses direitos. (CARLOS NETO; DENDASCK; OLIVEIRA, 2016).
\end{abstract}

Sobre o assunto, afirma Barcellos (2002, p. 161):

Sob o titulo geral da reserva do possível convivem ao menos duas espécies diversas de fenômenos. O primeiro deles lida com a inexistência fática de recursos, algo próximo da exaustão orçamentária, e pode ser identificado como uma reserva do possível fática. É possível questionar a realidade dessa espécie de circunstancia quando se trata do poder público, tendo em conta a forma de arrecadação de recursos e a natureza dos ingressos públicos. Seja como for, a inexistência absoluta de recursos descreveria situações em relação às quais se poderia falar de reservado possível fática.

O segundo fenômeno constata uma reserva do possível jurídica, já que não reproduz propriamente um estado de exaustão de recursos, e sim a falta de autorização orçamentária para certo gasto em particular.

Sendo assim, o princípio da reserva do possível é uma delimitação fática e jurídica que o Estado se vale para deixar de conceder os direitos sociais a quem de direito. Esta é a 
grande dificuldade aqui suscitada, pois se refere às numerosas alegações pelo Poder Público deste princípio, apenas para escusar-se da obrigação da realização dos direitos fundamentais sociais.

É necessário na próxima abordagem o assunto referente ao mínimo existencial para a garantia dos Direitos Sociais, tema de muita importância para este artigo é o que será estudado a seguir.

Partindo-se da ideia de que as necessidades da população são imensuráveis e os recursos limitados, deve-se ter em mente sobre como determinar as prioridades na destinação dos recursos de forma a garantir o mínimo determinado na Constituição Federal.

Primeiramente, aponte-se que a formulação do conceito de mínimo existencial teve origem na Corte Constitucional Alemã, que extraiu o direito a um mínimo de existência do principio da dignidade da pessoa humana (Lei Fundamental, art. 1, I) e do direito a vida e a integridade física, mediante interpretação sistemática junto ao principio do estado Social (LF, art. 20, I) (KRELL apud CARLOS NETO; DENDASCK; OLIVEIRA, 2016).

Complementando o entendimento:

\begin{abstract}
Num primeiro momento, a qualificação, a qualificação da dignidade da pessoa humana como principio fundamental traduz a certeza de que o art. $1^{\circ}$, inc. III, de nossa Lei fundamental não contem apenas uma declaração de conteúdo ético e moral (que ela, em ultima analise, não deixa de ter), mas que constitui norma jurídicopositiva com status constitucional e, como tal, dotada de eficácia, transformando-se de tal sorte, para além da dimensão ética já apontada, em valor jurídico fundamental da comunidade. Importa considerar neste contexto, que, na condição de principio fundamental, a dignidade da pessoa humana constitui valor-guia não apenas dos direitos fundamentais, mas de toda ordem constitucional, razão pela qual se justifica plenamente sua caracterização como principio constitucional de maior hierarquia axiológico-valorativa. (SARLET, 2007, p. 111-112)
\end{abstract}

Isto é, o mínimo existencial está conectado à dignidade da pessoa humana e deve ser preservado pelos direitos sociais prestacionais de forma a oferecer condições mínimas da população. Na tentativa de delimitar o conteúdo do mínimo existencial, uma solução possível é "a utilização do principio da dignidade da pessoa humana para garantir as condições mínimas da população para uma vida saudável", sugerindo como diretriz mínima os parâmetros estabelecidos pela Organização Mundial de Saúde. (CARLOS NETO; DENDASCK; OLIVEIRA, 2016).

Mesmo assim continua a haver largo espaço para a conformação política do legislador, visto não haver "uma medida certa nem uma forma única de cumprimento do imperativo 
constitucional", ou seja: não há um conteúdo fixo do direito ao mínimo para uma existência condigna, que só será delimitado no caso concreto. (ANDRADE, 2002, p. 27)

De toda sorte, o padrão mínimo social para a sobrevivência terá de incluir sempre um atendimento básico e eficaz de saúde, o acesso a vestimentas e uma alimentação básica, a educação de primeiro grau e a garantia de uma moradia, conforme abaixo:

\begin{abstract}
Ora, se a sociedade não for capaz de reconhecer a partir de que ponto as pessoas se encontram em uma situação indigna, ou seja, se não houver consenso a respeito do conteúdo mínimo da dignidade, "estar-se-á diante de uma crise ética e moral de tais proporções que o principio da dignidade da pessoa humana terá se transformado em uma formula totalmente vazia". (BARCELLOS, 2002, p. 197)
\end{abstract}

Logo, o mínimo social assegurado nas condições materiais de existência ficaria baseado no conceito de dignidade da pessoa humana, e a retórica desse mínimo não desdenharia os direitos sociais, mas antes, os consolidaria em sua dimensão essencial como expressão de uma cidadania requerida.

Garantido constitucionalmente, o mínimo existencial deve ser atendido com prioridade, é o que diz Barcellos (2002, p. 197):

Se é assim, e os meios os meios financeiros não são ilimitados, os recursos disponíveis deverão ser aplicados prioritariamente no atendimento dos fins considerados essenciais pela Constituição, até que eles sejam realizados.

Os recursos remanescentes haverão de ser destinados de acordo com as opções politicas que a deliberação democrática apurar em cada momento.

Os recursos remanescentes terão de ser designados de acordo com as opções politicas que a deliberação democrática averiguar em cada momento.

Levando em consideração que o mínimo existencial, inerente às garantias constitucionais prioritárias (direitos básicos prestacionais), possui aplicabilidade instantânea por serem direitos indispensáveis independentemente se sociais ou não. No entanto, quanto às prestações não se tratarem de direitos sociais vinculados ao mínimo existencial, aí sim estarão condicionados as limitações dos recursos orçamentários. (CARLOS NETO; DENDASCK; OLIVEIRA, 2016).

Porém, é do Poder Público o dever de cumprir o que a constituição garante como afirma Krell (2002, p. 60): 
Onde o Estado cria essas ofertas para a coletividade, ele deve assegurar a possibilidade da participação do cidadão. E caso a legislação não conceder um direito expresso ao individuo de receber uma prestação vital, o cidadão pode recorrer ao direito fundamental de igualdade em conexão com o principio do Estado Social.

Uma vez infringido o mínimo existencial, pela falta da efetividade dos direitos fundamentais sociais, surge o direito de exigi-lo judicialmente.

O motivo que justifica tal judicialização dos direitos sociais, inerentes ao mínimo existencial, se dá em virtude de que esses direitos são imprescindíveis para se ter uma vida com dignidade, razão pela qual a teoria da reserva do possível aqui não se submete. Embora, esta judicialização tentar diminuir o problema da falta de recursos, tem que se ter vista também sobre quais os fins essenciais previstos na Constituição, bem como se os recursos são suficientes para atender os fins previstos. (BOTELHO apud CARLOS NETO; DENDASCK; OLIVEIRA, 2016).

Mas é diante do mínimo existencial que será avaliado as prioridades para os gastos públicos, com base na Constituição, e também será capaz de se delimitar a atuação jurisdicional de defesa dos direitos sociais.

Segundo Canotilho (2002) o Estado deve garantir a eficácia dos direitos sociais como já sabe, mas vale dizer, também, que o mesmo não pode reduzir anular ou revogar o que hoje se entende como mínimo existencial devendo vedar todas as medidas legislativas tendentes a isso. Este é o principio da proibição do retrocesso social.

Considerando-se a vedação do retrocesso, afirma-se:

A vedação do retrocesso, por fim, é uma derivação da eficácia negativa,
particularmente ligada aos princípios que envolvem os direitos fundamentais. Ela
pressupõe que esses princípios sejam concretizados através de normas
infraconstitucionais e que, com base no direito constitucional em vigor, um dos
efeitos gerais pretendidos por tais princípios é a progressiva ampliação dos direitos
fundamentais. Partindo desses pressupostos, o que a vedação do retrocesso propõe
se possa exigir do Judiciário é a invalidade da revogação de norma que,
regulamentando o principio, concedam ou ampliem direitos fundamentais, sem que a
revogação em questão seja acompanhada de uma politica substitutiva ou
equivalente. (BARROSO apud CARLOS NETO; DENDASCK; OLIVEIRA, 2016).

Conclui-se, então, que esta vedação do retrocesso é uma maneira de vetar a revogação das leis que garantem os direitos sociais, para que não se reduza o que já se foi conquistado através da evolução histórica, como padrões mínimos estabelecidos para se ter uma vida com dignidade. 


\section{RESPONSABILIDADE DO ESTADO EM MATÉRIA DE SAÚDE}

A Constituição Federal de 1988, após colocar como um dos princípios basilares do Estado Democrático de Direito “a dignidade da pessoa humana” (artigo $1^{\circ}$, III), enuncia o rol dos direitos e garantias fundamentais a partir da "inviolabilidade do direito à vida (artigo $5^{\circ}$, caput)". E na sequência, a Constituição enumera o rol dos direitos sociais, neles incluindo a "saúde" (artigo $6^{\circ}$ ), cujos lineamentos constam de outras disposições em título próprio.

Na mesma linha de proteção, nossa Carta Magna, sob o título: "Da ordem social”, dispõe em seus artigos 193 e seguintes que: “a seguridade social compreende um conjunto integrado de ações de iniciativa dos Poderes Públicos e da sociedade destinadas a assegurar os direitos relativos à saúde, à previdência e à assistência social”."

Está aplicado, dessarte, em aparelhos explícitos de nosso ordenamento maior, que se avaliza o direito humano à saúde, competindo ao Estado dar efetividade a esse direito em todos os seus níveis, seja como conceitos de cunho preventivo ou como em medidas de recuperação da pessoa ofendida em suas qualidades físicas ou psíquicas, todas essenciais a uma vivência digna.

A Lei $\mathbf{n}^{\circ}$. 8.080/90 dispõe sobre o Sistema Único de Saúde (SUS) previsto no artigo 198 da Constituição Federal, dando-lhe a necessária implantação para funcionamento garantidor da proteção à saúde. Seu artigo $2^{\circ}$ reafirma o preceito constitucional de que " $a$ saúde é um direito fundamental do ser humano, devendo o Estado prover as condições indispensáveis ao seu pleno exercício”. (BRASIL, 1990)

Explicita o $\S 1^{\circ}$ desse artigo que:

[...] o dever do estado de garantir a saúde consiste na formulação e execução de políticas econômicas e sociais que visem à redução de riscos de doenças e de outros agravos e no estabelecimento de condições que assegurem acesso único e igualitário às ações e aos serviços para sua promoção, proteção e recuperação. (BRASIL, 1990)

Para tanto é que se definiu o citado "Sistema Único de Saúde”, como um conjunto de ações e serviços sanitários a cargo de órgãos e instituições públicas federais, estaduais e municipais, da Administração Direta e Indireta e de fundações mantidas pelo Poder Público $\left(\operatorname{artigo} 4^{\circ}\right)$. (OLIVEIRA, 2019) 
Dentre as atribuições do SUS, a par da vigilância sanitária e epidemiológica, situamse também a preservação da saúde do trabalhador e a prestação de assistência terapêutica integral, inclusive farmacêutica. (artigo $6^{\circ}$, inciso I, letra “ $d$ ”).

Cumpre apontar como diretriz da ação conjunta dos órgãos integrantes do SUS, a conjugação de recursos financeiros, tecnológicos, materiais e humanos dos três níveis de Poder para a prestação do serviço de saúde (artigo $7^{\circ}, \mathrm{XI}$ ). Sem esse suporte material e humano, com destaque para os recursos orçamentários, resultaria inócua a previsão de esforço concentrado para a meta de preservação da saúde da população. Faz parte essa implantação de cunho material, do sistema protetivo, a fim de dar efetividade em cumprimento ao mandamento constitucional de garantia do direito em exame. Sobre as fontes dos recursos e a gestão financeira do SUS dispõe os artigos 31 a 35 da Lei nº. 8.080/90. (OLIVEIRA, 2019)

$\mathrm{O}$ artigo 43 da mesma lei afirma a gratuidade da assistência devida pelo Estado, em termos incisivos: "a gratuidade das ações e serviços de saúde fica preservada nos serviços públicos e privados contratados, ressalvando-se as cláusulas dos contratos ou convênios estabelecidos com as entidades privadas".

Outros diplomas legais relacionados a questões de saúde podem ser citados em caráter meramente exemplificativo:

$\checkmark$ Lei $n^{\circ} .7 .802 / 89$, sobre o controle de agrotóxicos;

$\checkmark$ Lei $n^{\circ} .9 .273 / 96$, que torna obrigatória a inclusão de dispositivo de segurança para evitar a reutilização de seringas descartáveis; e

Lei $\mathrm{n}^{\circ}$. 9.313/96, sobre distribuição gratuita de medicamentos aos portadores e doentes de AIDS.

O surgimento dessa última lei deu-se em virtude de as associações de defesa de soropositivos terem iniciado intensa pressão junto ao Governo e ao Congresso, visando à aprovação da regulamentação da norma constitucional que previsse expressamente a distribuição, pelo poder público, de medicamentos necessários ao combate à AIDS. Em 13 de novembro de 1996, premido pela intensa mobilização da sociedade civil, finalmente o Governo fez vir a lume a Lei $\mathrm{n}^{\circ}$. 9.313, dispondo sobre "a distribuição gratuita de medicamentos aos portadores do HIV e doentes de AIDS”. (GOUVÊA, 2003)

Algumas observações devem ser feitas acerca do diploma legal transcrito. Ressaltese, em primeiro lugar, que a Lei $n^{\circ}$. 9.313/96 não estabelece qualquer distinção econômica entre os portadores do HIV: todos têm acesso ao recebimento gratuito dos medicamentos, 
independentemente da demonstração de necessidade, miserabilidade ou qualquer outra circunstância subjetiva. No $\S 1^{\circ}$ de seu artigo $1^{\circ}$, a lei estabelece que os medicamentos tornados disponíveis sejam aqueles constantes de relação padronizada do Ministério da Saúde, relação essa que deverá ser atualizada anualmente, ou sempre que novas descobertas científicas o recomendarem $\left(\S 2^{\circ}\right)$. Ela prevê, por fim $\left(\operatorname{artigo} 2^{\circ}\right)$, que os recursos para a aquisição dos remédios serão oriundos dos orçamentos da seguridade social da União, dos Estados e dos Municípios, "conforme regulamento". (GOUVÊA, 2003)

O direito à saúde, de forma irrestrita, nasce considerado como direito fundamental social no artigo 6", "caput” e no artigo 196 da Constituição Federal, devendo o Estado prover as condições indispensáveis ao seu pleno exercício.

Outras manifestações importantes podem ser destacadas:

$\checkmark \quad$ Lei $n^{\circ} .9 .431 / 97$, relativa a programas de controle de infecções hospitalares;

$\checkmark \quad$ Lei $n^{\circ} .9 .434 / 97$, sobre remoção de órgãos e transplantes;

$\checkmark \quad$ Lei $n^{\circ} .9 .797 / 99$, estabelecendo obrigatoriedade da cirurgia plástica reparadora da mama pela rede do SUS;

$\checkmark \quad$ Lei no $.9 .961 / 00$, que regula a Agência Nacional de Saúde Suplementar (ANS).

Os princípios e regras basilares da Constituição Federal constam igualmente, e em caráter suplementar, das Constituições Estaduais e de Códigos de Saúde estaduais e municipais, além de vasta legislação esparsa sobre normas de caráter sanitário. (OLIVEIRA, 2019)

O Brasil é uma República Federativa, isto é, optou pela Federação como forma de organização político-administrativa. O Federalismo, como expressão de Direito Constitucional, baseia-se na união de coletividades políticas autônomas. (BARTOLOMEI, 2004)

Os entes federativos são: União, Estados Federados, Distrito Federal e Municípios.

Leciona Horta (2003, p. 756) que a União é a entidade federal formada pela reunião das partes componentes, constituindo pessoas jurídicas de Direito Público interno, autônoma em relação aos demais entes federativos e a quem cabe exercer as prerrogativas da soberania do Estado brasileiro.

No federalismo, as competências são distribuídas necessariamente entre os entes públicos e podem ocorrer de maneira coordenada ou cooperada. A Carta Magna descreve, expressamente, as competências de cada esfera de poder público. Esta distribuição 
constitucional de poderes é o ponto nuclear de Estado Federal. Assim, no federalismo cooperativo tem-se que os resultados buscados são comuns e do interesse de todos. A decisão tomada em escala federal é adaptada e executada autonomamente pelo ente federado, adequando-se às suas peculiaridades e necessidades. Este tipo de repartição é chamado de competência concorrente e está prevista no artigo 24 da Constituição de 1998. Já no artigo 23, nas chamadas competências comuns revela-se a cooperação. Nesta, a decisão é de todos, mas a execução se realiza separadamente, muito embora possa haver no que se refere ao financiamento das políticas públicas, uma atuação conjunta. (BARTOLOMEI, 2004)

Quanto à extensão, as competências podem ser:

a) Exclusiva: quando é atribuída a uma entidade com exclusão das demais (artigo $21, \mathrm{CF} / 88)$.

b) Privativa: quando enumerada como própria de uma entidade, com possibilidade de delegação e competência suplementar (artigo 22 e $\S \S, C F / 88$ );

c) Comum cumulativa ou paralela: campo de atuação comum aos vários entes, sem que o exercício de um venha a excluir a competência do outro, que pode assim ser exercida cumulativamente (artigo 23, CF/88);

d) Concorrente: possibilidade de disposição sobre o mesmo assunto ou matéria por mais de uma entidade federativa. Contudo, há primazia da União no que tange à fixação de normas gerais (artigo 24 e $\S \S, \mathrm{CF} / 88$ );

e) Suplementar: para suprir ausência ou omissão (artigo $24, \S \S 1^{\circ}$ ao $4^{\circ}, \mathrm{CF} / 88$ ).

Com base nessa classificação têm-se as seguintes competências ligadas à saúde:

$\checkmark$ Competência comum:

Art. 23. É competência comum da União, dos Estados, do Distrito Federal e dos Municípios:

[...]

II- cuidar da saúde e assistência pública, da proteção e garantia das pessoas portadoras de deficiência.

$\checkmark \quad$ Competência legislativa concorrente:

Art. 24 Compete à União, aos Estados e ao Distrito Federal legislar concorrentemente sobre:

$[\ldots]$

XII- previdência social, proteção e defesa da saúde;

$[\ldots]$

$\S 1^{\circ}$ No âmbito da legislação concorrente, a competência da União limitar-se- á a estabelecer normas gerais. 
$\S 2^{o}$ A competência da União para legislar sobre normas gerais não exclui a competência suplementar dos Estados.

Competência exclusiva municipal:

Art 30. Compete aos Municípios:

[...]

VII- prestar, com a cooperação técnica e financeira da União e do Estado, serviços de atendimentos à saúde da população.

Ressalvar que a CF/88 não incluiu qualquer órgão federativo da obrigação de proteger, defender e cuidar da saúde. A ação ligada e ordenada entre União, Estados, Distrito Federal e Municípios é uma cominação constitucional. Assim, a saúde, é dever do Estado (artigo 196) e responsabilidade de todos.

$\mathrm{O}$ artigo $5^{\circ}, \mathrm{XXXV}$, da Constituição Federal proíbe a lei de excluir da apreciação do Poder Judiciário, lesão ou ameaça a direito. (Princípio da Inafastabilidade da Jurisdição, também conhecido por direito de ação ou princípio do livre acesso ao Judiciário).

Esse dispositivo garante a todos o acesso à justiça para postular e defender os seus interesses, por meio de tutela específica.

Podem ser mencionados, entre outros e sem anseio de exaurir a casuísta, os adjacentes meios judiciais de entrada à proteção ao direito à saúde:

\section{Direito de petição}

\section{Mandado de Segurança}

Mandado de Injunção

Ação Civil Pública (Lei no. 7.347/85);

\section{Medida Cautelar Inominada}

\section{Ação Ordinária}

\section{Tutela antecipada}

artigo $5^{\circ}, \mathrm{XXXIV/CF;}$

artigo $5^{\circ}$, inciso LXIX/ CF;

artigo $5^{\circ}$,inciso LXXI /CF;

artigo 297 do CPC;

art. $1.046, \S 1 .^{\circ}$ e 1.049 , relacionados

artigo $5^{\circ}$, incisos XXXV e LXXVIII da

$\mathrm{CF}$

Em medical progresso legislativo e na fronteira que já procedia pela doutrina moderna e procurando a concretude dos princípios constitucionais da efetividade e da economia processuais, a Lei $n^{\circ}$. 10.444, de 7 de maio de 2002, acrescentou ao artigo 273, do CPC, que aborda da antecipação de tutela, o $\S 7^{\circ}$, que comporta ao juiz apor o princípio da fungibilidade, dada a urgência, reconhecendo o grau de urgência, independente do rótulo 
“nomem iuris" empregado, se tutela antecipada ou cautelar e o artigo correspondente ao atual Código de Processo Civil é artigo 300.

\section{A JUDICIALIAÇÃO DO DIREITO À SAÚDE}

Observa-se que a Constituição Federal de 1988 se mostra como um marco muito relevante nesse cenário, nas ideias de Zanotelli (2018, p. 41), "considerando a narrativa histórica que evidencia ter a mesma elevado o direito à saúde ao patamar de direito humano".

A questão relacionada à judicialização é um acontecimento mundial que vem repercutindo na área de saúde, observa-se que a judicialização traz consequências consideradas danosas à área saúde.

Dentro desse contexto, segundo Barroso (2009), a “judicialização acontece, porque, cada vez mais, questões de larga repercussão social e política passam a ser decididas por órgãos judiciais e não pelas instâncias políticas tradicionais". Esse fenômeno apresenta múltiplas causas e expressa uma tendência mundial.

A ideia de judicialização se relaciona com a ideia de hipertrofia do poder judiciário, em detrimento dos outros poderes, existe uma expansão dos métodos judiciais de tomada de decisão que vai além do próprio domínio do judiciário. Observa-se que o Supremo Tribunal vem desempenhando um importante papel na vida institucional brasileira, em virtude da ausência de políticas públicas.

Cabe ainda mencionar que a atuação do Poder Judiciário vem provocando discussões em relação aos demais poderes, em virtude de uma suposta ausência de legitimação democrática para decidir sobre questões políticas, é dentro desse viés que a discussão sobre a judicialização e o ativismo judicial será realizada. A sagração da saúde na posição que ocupa no Brasil e no Mundo bem como os demais direitos humanos fundamentais, consequência de uma longa evolução do pensamento, da sociedade e do Estado Democrático de Direito.

Essa judicialização em relação à saúde é um fenômeno cuja ocorrência foi alcançada, em virtude do advento da Constituição Federal de 1988, que proporcionou ao direito à saúde a condição de direito fundamental. Nessa condição o Estado passa a preocupar-se com as questões relativas à saúde, na medida em que os entes federativos passam a ser partes do Sistema Único de Saúde. Os gastos relativos à saúde aumentaram de maneira vultosa, consequência natural da proteção constitucional que lhe é conferida. A finalidade é oferecer 
um atendimento universal e integral à população, criando a obrigação de manter os serviços básicos em funcionamento.

O cidadão, ao precisar de um medicamento e, diante de uma negativa ou recusa do Estado em fornecê-lo, naturalmente irá recorrer ao Poder Judiciário, sendo oportuno mencionar que a proteção constitucional dos direitos sociais é da mais alta relevância, não se podendo negar e nem tampouco diminuir sua importância.

\section{CONCLUSÃO}

Com o intuito de encerrar o presente artigo e a concepção como um todo apresentada até o momento serão em síntese expostos os temas abordados.

O direito à saúde, analisado como direito individual, beneficia a liberdade em sua mais vasta definição e, perante a ótica individual, o direito à saúde sugere a liberdade do profissional de saúde, a fim de determinar o início do tratamento. Ele necessita, consequentemente, de poder para apoiar-se em todas as opções possíveis, para eleger a mais apropriada. É evidente, portanto, que a essencial liberdade, indispensável ao direito à saúde, ao mesmo tempo em que é um direito subjetivo, decorre também do grau de desenvolvimento do Estado.

Restou-se claro, no estudo realizado, a categorização do direito à saúde como um direito fundamental da pessoa humana de forma a garantir o mínimo existencial. Tal direito integra o rol de tantos outros de há muito já positivados na Constituição Brasileira. Não se poderia imaginar o atendimento à igualdade, à proteção do direito à vida e à integridade física sem se vislumbrar, por motivo óbvio, seu vínculo ao direito à saúde.

O Estado é um provedor de igualdade social, cabendo-lhe o atendimento a direitos que lhe exigem condutas positivas. Cabe ao Estado, ainda, não apenas a não violação do direito à saúde, mas a obrigação de prove-la, seja através de politicas públicas, por parte do executivo, seja através da edição de leis constitucionais, que se enquadrem na órbita humana do Estado Social e do Estado Democrático de Direito.

Em nosso ordenamento maior, tal papel, pela sua importância, não há de ser reservado indistintamente a apenas alguns dos entes, mas distribuído a todos os componentes da Federação, incluindo-se, indubitavelmente, os municípios, posto serem os entes mais 
próximos da realidade social, devendo para tanto ocorrer um respeito às regras constitucionais relativas aos recursos públicos.

Estudou-se, também, o direito a saúde frente ao principio do mínimo existencial para se garantir a dignidade da pessoa humana e da reserva do possível e que, hoje, a judicialização de tal direito torna-se necessária para dirimir os conflitos que assolam o caos que se encontra a saúde pública do Brasil, pois constantemente as pessoas se veem em situações que necessitam de atendimento médico diferenciado, e mesmo quanto ao atendimento médico padrão, e não conseguem obter o mínimo necessário para tal atendimento.

\section{REFERÊNCIAS BIBLIOGRÁFICAS}

ANDRADE, José Carlos Vieira de. O Judiciário e os Direitos Fundamentais Sociais: Acesso à Saúde, questão polemica. Porto Alegre: Tribunal de Justiça, 2002.

BARCELlOS, Ana Paula de. A Eficácia Jurídica dos Princípios Constitucionais: o Princípio da Dignidade da Pessoa Humana. Rio de Janeiro: Renovar, 2002.

BARROSO, Luís Roberto. Judicialização, Ativismo Judicial e Legitimidade Democrática, 2009.

BARTOLOMEI, Carlos Emmanuel Fontes. Legislação em Saúde. Carlos Emmanuel Fontes Bartolomei, Maria Célia Delduque, Mariana Siqueira de Carvalho, Hélcio de Abreu Dallari Júnior. 2. ed. São Paulo: BIREME/OPAS/OMS, 2004.

BOBBIO, Norberto. A era dos direitos. Tradução de Carlos Nelson Coutinho. Rio de Janeiro: Campos, 1992.

BRASIL. Lei $n^{o}$ 8.080, de 19 de setembro de 1990. Dispõe sobre as condições para a promoção, proteção e recuperação da saúde, a organização e o funcionamento dos serviços correspondentes e dá outras providências. Disponível em: http://www.planalto.gov.br/ccivil_03/leis/L8080.htm. Acesso em: 20 ago. 2019.

CANOTILHO, José Joaquim Gomes. Direito Constitucional e Teoria da Constituição. 6.ed. Coimbra: Almedina, 2002.

CARLOS NETO, Daniel; DENDASCK, Carla; OLIVEIRA, Euzébio de. A eficácia dos direitos sociais na saúde pública. Revista Científica Multidisciplinar Núcleo do Conhecimento - Vol. 01, Ano 01, Ed. 03, pp: 03-14, Março de 2016. 
DALLARI, Sueli Gandolfi. O direito à saúde. Rev. Saúde Pública vol.22 no.1 São Paulo Feb. 1988.

GOUVÊA, Marcos Maselli. O Direito ao Fornecimento Estatal de Medicamentos. In: Revista Forense, vol. 370. Rio de Janeiro: Forense, 2003.

HORTA, Raul Machado. Direito constitucional. $4^{\mathrm{a}}$ ed. rev. e atual. Belo Horizonte: Del Rey, 2003.

KELSEN, Hans. Teoria pura do direito. São Paulo: Martins Fontes, 1985.

KRELL, Andrea Joachim. Direitos Sociais e Controle Judicial no Brasil e na Alemanha: os (des)caminhos de um direito constitucional comparado. Porto Alegre: Sérgio Antonio Fabris, 2002.

OLIVEIRA Euclides Benedito de. Responsabilidade do Estado pelo atendimento integral à saúde da pessoa humana. Disponível em: http://www.familiaesucessoes.com.br/?p=869. Acesso em: 20 ago. 2019.

REALE, Miguel. Lições preliminares de direito. São Paulo: Saraiva. 1976.

SARLET, Ingo Wolfgang. A Eficácia dos Direitos Fundamentais. 7. ed. Porto Alegre: Livraria do Advogado, 2007.

SILVA, José Afonso da. Comentário Contextual à Constituição, São Paulo: Malheiros, 2006.

SLAIBI, Maria Cristina Barros Gutiérrez. O direito fundamental à saúde. Disponível em: http://periodicos.ses.sp.bvs.br/pdf/bis/v12n3/v12n3a03.pdf. Acesso em: 20 ago. 2019.

ZANOTELLI, Beatriz Graeff; NISTLER, Regiane. A judicialização do direito à saúde. Erechim: Deviante, 2018. 